\title{
Reference Chart for the Apparent Motions of the Sun, Moon and Planets
}

By Dr. B. K. VAIDYE, Indian Institute of Science, Bangalore

$\mathrm{T}$ HE apparent motions of the sun, the moon and the planets during the course of a year can be represented very conveniently by plotting on a single sheet of paper the right ascension of these bodies corresponding with each day of the year. The planetary chart prepared in this way gives a picture of the sky for the whole year, so far as the principal members of the solar system are concerned, and besides, it shows at a glance all the planetary phenomena and the days when they occur.

Fig. 1 shows such a chart for the year 1934. It forward motion they are in superior conjunction with the sun, while during a downward or retrograde course they pass through an inferior conjunction at the point of intersection with the sun line. The proper dates and periods for these and other phenomena are read off on the abscissa.

In other respects the chart is self-explanatory. The dates for the mutual conjunctions of the planets and for their conjunctions with the sun and the moon are given by various points of intersections. The stationary points at the two extremities of a retrograde path are marked $S$. The time of opposition

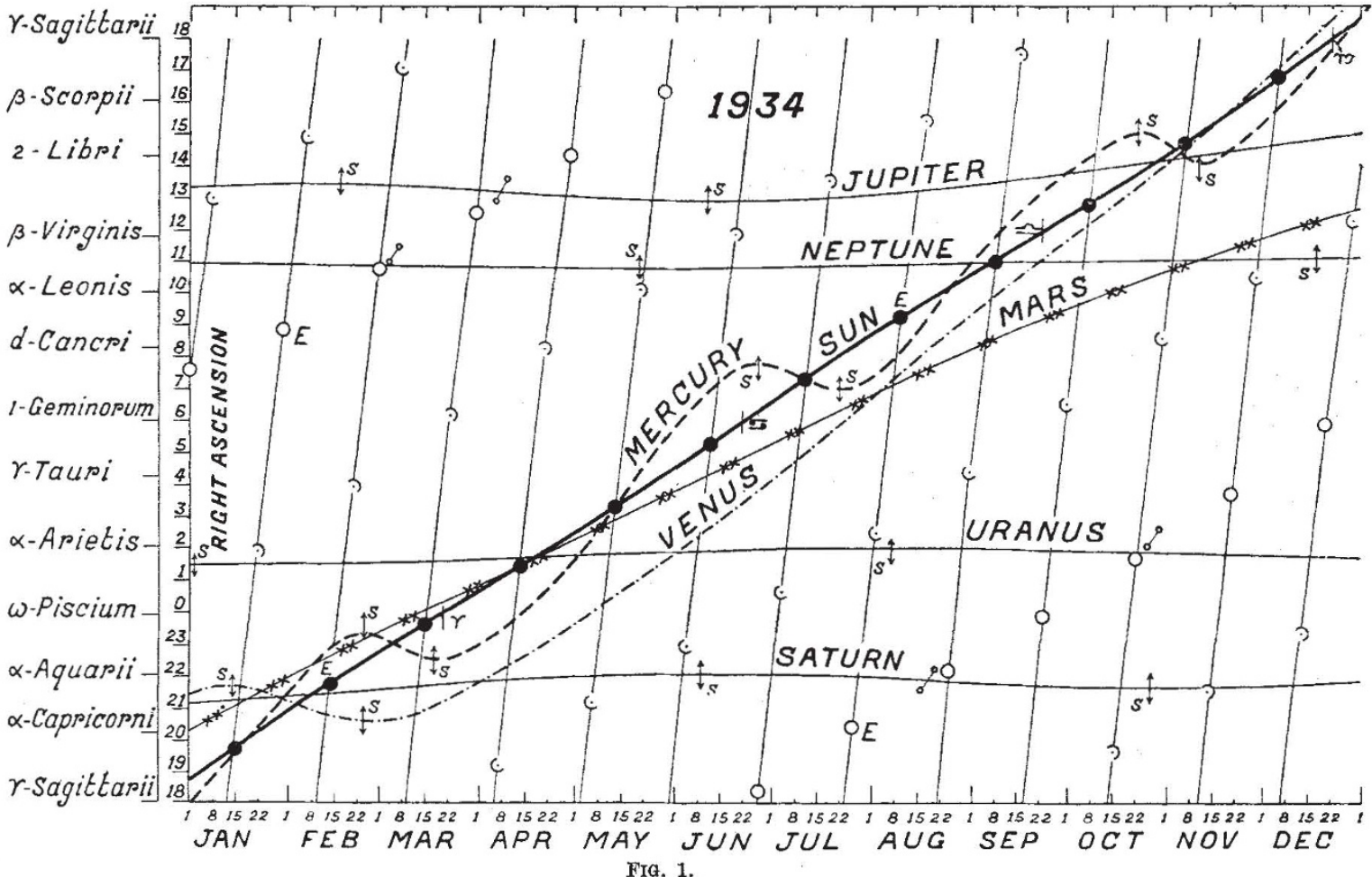

is not possible to include in the diagram the variations in the declinations of the objects, but this need cause little interference, as the movements considered here lie within the comparatively narrow region around the ecliptic. Along with the right ascension hours on the ordinate are given the names of twelve stars in the zodiacal constellations. These stars are placed at a distance of approximately two-hour angles in succession, and lie at points which are very near the ecliptic. They serve to locate the positions of the planets, the sun and the moon at any desired day of the year.

The most interesting types of curves are described by the two inferior planets, Mercury and Venus. Their motions lie alternately above (eastern elongation) and below (western elongation) the sun's line of motion, corresponding to the periods when they appear as the evening and morning stars, respectively. The greatest elongations are reached on the days when their distances from the sun line are a maximum. When their paths intersect the sun line during a to the sun is marked by the appropriate symbol. The moon's path, with the four principal phases, is shown by a number of slanting lines crossing the whole of the diagram. The solar and the lunar eclipses are marked by the letter $E$ near a new moon or a full moon. The times of the equinoxes and the solstices are indicated by the conventional zodiacal symbols.

The time of the rising or the setting of a planet on any particular day may be ascertained by finding its distance from the sun on the day in question. This distance gives directly the duration in hours for which the planet would be visible above the horizon, after the sunset or before the sunrise according to its position above or below the sun line. Thus it may be seen from the diagram that at the end of January 1934 a remarkable phenomenon occurs when the sun is closely followed by the four planets, Mercury, Venus, Saturn and Mars, the first three of these setting about half an hour and the last about an hour after the sun. 
ground, but without any of the unpleasant feelings associated with the word giddiness.

In people who are particularly susceptible, vertigo accompanied even by nausea and vomiting may easily be brought about by kinæsthetic impulses or by moving visual stimuli. But that the labyrinth is by far the most usual and important sense organ from which vertigo is aroused, and probably the only one concerned in sea-sickness, is now firmly established. James, Kreidl and Myginol have all commented on the immunity from sea-sickness of deafmutes in whom the labyrinths were deficient. The experiments of Dreyfuss on guinea-pigs and of
Kreidl on dogs, cats and pigeons pointed in the same direction. Decerebration, decerebellation, or section of both vagi leaves sea-sickness unaffected, but removal of both labyrinths or section of both eighth nerves results in complete immunity. The most likely explanation of the vomiting seems to be that it is caused by spread of excitation from the vestibular nuclei to the neighbouring medullary 'vomiting centre'.

As a result of the interest aroused in the discussion, a joint research committee of the Sections of Physiology and Psychology has been set up to investigate the conditions of vertigo and its relation to dis. orientation.

\section{Fishes of Mountain Streams}

$\mathrm{D}^{\mathrm{R}}$ R. SUNDER LAL HORA, of the Zoological Survey of India, has for many years devoted special attention to the study of the fauna of rapidly running waters in the hill streams of India. His knowledge of this difficult and interesting branch of zoology is unrivalled. No one, therefore, could be better qualified than he to undertake a detailed investigation* of that remarkable group of cyprinoid fishes, the Homalopteridæ. These fishes, inhabitants of swiftly running mountain streams of southern Asia, have undergone a great variety of adaptive modifications induced by the peculiar environmental conditions typical of their habitat.

In the first part of his report the author deals with the taxonomy of the group. It is divided into 2 sub-families-the Homalopterinæ, comprising 6 genera and 31 species, and the Gastromyzoninæ which is represented by 11 genera having in all about 16 species. In the Homalopterinæ 4 new species belonging to the genera Homaloptera and Lepturichthys, and 2 new varieties of Balitora brucei are described. Among the Gastromyzoninæ no new species have been found; but in order properly to classify the existing species 5 new genera are proposed in this paper. No attempt has been made to describe in full each and every species, but wherever an amplification of the already existing description seemed to the author to be desirable the species is

* Memoirs of the Indian Museum, vol. 12, No. 2, pp. 263-330. "Classifleation, Bionomics and Evolution of Homalopterid Fishes". By Sunder Lal Hora. Calcutta ; December, 1932. either redescribed or a note is inserted concerning some of its most important features.

In the second part of the paper the bionomies and evolution of the Homalopteridæ are discussed at some length. The most characteristic features of its members such as flattened shape, insertion of the pectoral fins (which are used for adhesion) far forward below or even in front of the eyes, possession of a peculiar rostral groove in front of and continued along each side of the mouth, the peculiar structure of the hard and strong lower jaw, are shown to be definitely correlated with the three most important factors in the environment-strong current, high oxygen content, and nature of the food supply available. Throughout the paper attention is repeatedly directed to the 'communal convergence' that is exhibited by these fishes and to the series of characters showing parallel development in the members of the two sub-families. From all the evidence which he has acquired the author believes that the Homalopteridæ are probably a polyphyletic family the members of which are derived from the Cyprinidæe and Cobitidæ and have come to resemble one another superficially under the influence of the same environmental conditions.

Dr. Hora is to be congratulated on having produced a paper which is not only a valuable addition to the literature on the taxonomy of the Homalopteridæ but is also of great theoretical interest.

G. A. S.

\section{Geological Reconnaissance by Aeroplane in Australia*}

$I^{\mathrm{N}}$ 1932 the Royal Australian Air Force made flights over many of those areas in Australia which are deemed to be worthy of investigation from the point of view of the discovery of oil. Dr. W. G. Woolnough, who was present as observer and geologist, has now detailed the results obtained in a report which gives valuable information regarding the function and importance of aerial work in assisting and expediting geological survey. The object was to determine the disposition of strata and especially to locate dome structures, the investigation being made partly by visual observation and partly by the study of the photographs taken from the air. Much experience is required before the utmost can be achieved by these methods, and Dr. Woolnough states that he scarcely began to appreciate the significance of details seen from above until he had completed one hundred hours of flying.

* Commonwealth of Australia. Report on Aerial Survey Operations In Australia during 1932. By Dr. W. G. Woolnough. (Canberra: Government Printers.)
From July until September, a circuit of Australia was made-also a visit to Tasmania, atmospheric conditions on the whole being favourable. Over Melville Island observation was hindered by a tribal fight, as part of the strategy consisted in the lighting of extensive bush fires, the smoke of which provided nuclei for the condensation of moisture and the development of clouds. The orientation of the photographs and the elevation of hills and scarps above the surrounding country can be determined by noting the direction and lengths of shadowsprovided the time of exposure is accurately known.

In those regions where the rocks are well exposed and where topographical forms are the direct result of the differential erosion of beds, the main tectonic features are easily seen, and examination of the photographs reveals where the detailed ground investigation which is essential to the full elucidation of the structure should be undertaken. Most valuable is the clearness with which the true disposition and 